\begin{tabular}{|c|l|}
\hline Title & An ultra high-energy collimator for small animal imaging in dual-isotope study of 18F and 99mTc \\
\hline Author(s) & Kubo, Naoki; Zhao, Songji; Kinda, A kiy oshi; Motomura, Nobutoku; Katoh, Chietsugu; Kuge, Yuji; Tamaki, Nagara \\
\hline Citation & $\begin{array}{l}\text { International Congress Series, 1264, 275-279 } \\
\text { https://doi.org/10.1016/.ics.2004.01.003 }\end{array}$ \\
\hline Issue Date & 200403 \\
\hline Doc URL & http://hdl.handle.net/2115/14713 \\
\hline Type & article (author version) \\
\hline File Information & ICS2004.1264.pdf \\
\hline
\end{tabular}

Instructions for use 


\section{An ultra-high-energy collimator for small animal imaging in dual-isotope study of ${ }^{18} \mathrm{~F}$ and ${ }^{99 \mathrm{~m}}$ Tc.}

Naoki Kubo*, Songji Zhao, Akiyoshi Kinda, Nobutoku Motomura, Chietsugu Katoh, Yuji Kuge and Nagara Tamaki

Hokkaido University, Sapporo, Japan; Toshiba, Tochigi, Japan; Kyoto University, Kyoto, Japan.

single photon emission computed tomography; pinhole collimator; small animal imaging; Fluorine-18 deoxyglucose; dual-isotope imaging

Abstract. We have developed a pinhole collimator for small animal imaging using dual-isotopes such as gamma and positron emitters. A lead cylinder containing a pinhole was placed around the subject (a small animal). The cylinder was equipped with a non-collimator gamma camera and dual-isotope $\left({ }^{99 \mathrm{~m}} \mathrm{Tc}-\mathrm{MIBI}\right.$ and $\left.{ }^{18} \mathrm{~F}-\mathrm{FDG}\right)$ SPECT was performed on a Wistar King Aptekman/hok (WKAH) rat. System planar sensitivity and Full-Width at Half-Maximum (FWHM) were measured for each radionuclide. System planar sensitivities for ${ }^{99 \mathrm{~m}} \mathrm{Tc}$ and ${ }^{18} \mathrm{~F}$ SPECT were 2 and $7 \mathrm{cps} / \mathrm{MBq}$, respectively. FWHMs for ${ }^{99 \mathrm{~m}} \mathrm{Tc}$ and ${ }^{18} \mathrm{~F}$ SPECT were $2.0 \pm 0.5$ and $2.7 \pm 0.5 \mathrm{~mm}$, respectively. The collimator is relatively light (23 kg) and thus SPECT projection data could be acquired by rotating the gamma camera while the object remained stationary. The pinhole collimator can be used with a conventional rotating gamma camera. The present study demonstrated that it is possible to image organs in vivo in sufficient detail using the newly developed pinhole collimator. Further refinements to the experimental procedure may provide simultaneous high-resolution imaging of small animals using positron and gamma emitters with this collimator.

\section{Introduction}

Recently, small animal imaging research has focused on basic nuclear medicine techniques [1-5]. One technique, dual-isotope imaging, traces two different radiopharmaceuticals (a positron emitter and a gamma emitter) under the same experimental conditions [6-8]. We have developed a pinhole collimator suitable for small animal imaging in such studies.

\section{Materials and methods}


Collimator design. A lead cylinder was placed around the subject (a small animal). The cylinder contained a pinhole (Fig. 1). The pinhole diameter of this knife-edge aperture was $0.6 \mathrm{~mm}$. The acceptance angle was $13^{\circ}$. The thickness of the lead shielding was $30 \mathrm{~mm}$. This cylinder was equipped with a non-collimator gamma camera at a distance of $30.5 \mathrm{~cm}$ (Fig. 2). The radius of rotation was $6 \mathrm{~cm}$. The magnification was 5.1 times.

Collimator weight. The collimator was relatively light $(23 \mathrm{~kg})$, thus enabling SPECT projection data to be acquired by rotating the gamma camera while the object remained stationary.

Sensitivity. The system planar sensitivities for ${ }^{99 \mathrm{~m}} \mathrm{Tc}$ and ${ }^{18} \mathrm{~F}$ were measured individually using point sources.

Spatial resolution of SPECT. SPECT acquisitions ( $128 \times 128$ matrix, 90 projections) were reconstructed using the Feldkamp method. FWHMs for ${ }^{99 \mathrm{~m}} \mathrm{Tc}$ and ${ }^{18} \mathrm{~F}$ were measured individually using line sources.

In vivo SPECT study. Dual-isotope SPECT was performed on a Wistar King Aptekman/hok (WKAH) rat (weight: $67 \mathrm{~g}$ ) injected ${ }^{99 \mathrm{~m}}$ Tc-MIBI (83 MBq) and ${ }^{18}$ F-FDG (11 MBq). SPECT data were acquired using a $128 \times 128$ matrix. SPECT was performed with repeated acquisition (10 min/rotation $\times 3$ times). Down scatter correction for ${ }^{99 \mathrm{~m}} \mathrm{Tc}$ was performed using a line-spread function subtraction method. Attenuation and scatter corrections were not performed. SPECT images were reconstructed using the Feldkamp method. The trans-axial images were reoriented into coronal images. The matrix size was $0.5 \mathrm{~mm}$ and the coronal slice thickness was $4 \mathrm{~mm}$.

\section{Results}

Sensitivity. System planar sensitivities of ${ }^{99 \mathrm{~m}} \mathrm{Tc}$ and ${ }^{18} \mathrm{~F}$ were 2 and $7 \mathrm{cps} / \mathrm{MBq}$, respectively.

Spatial resolution of SPECT. FWHMs of ${ }^{99 \mathrm{~m}}$ Tc and ${ }^{18} \mathrm{~F}$-SPECT were $2.0 \pm 0.5$ and 2.7 $\pm 0.5 \mathrm{~mm}$, respectively.

In vivo SPECT study. The present study showed that it is possible to image organs in vivo in sufficient detail using the pinhole collimator developed by the authors (Fig.3).

\section{Discussion}

We developed a pinhole collimator for use in small animal imaging with dual-isotope sources of positron and gamma emitters. The subject is restrained in the system, thus allowing procedures such as blood sampling and respiration monitoring to be easily performed on the animal. 
FWHM for ${ }^{99 \mathrm{~m}} \mathrm{Tc}$ was greater than the pinhole diameter. The probable cause for this was incomplete center of rotation (COR) correction.

\section{Conclusions}

We developed a pinhole collimator for small animal imaging in a dual-isotope system using gamma and positron emitters. The collimator is suitable for use with a conventional rotating gamma camera.

\section{Acknowledgment}

This study was supported in part by a Grant-in-Aid for Scientific Research (B) 13557073, from the Japan Society for the Promotion of Science (JSPS).

\section{References}

1. Wu MC, Gao DW, Sievers RE, Lee RJ, Hasegawa BH, Dae MW. Pinhole single-photon emission computed tomography for myocardial perfusion imaging of mice. J Am Coll Cardiol 2003; 42(3):576-582.

2. Wu MC, Hasegawa BH, Dae MW. Performance evaluation of a pinhole SPECT system for myocardial perfusion imaging of mice. Med Phys 2002; 29(12):2830-2839.

3. Liu Z, Kastis GA, Stevenson GD, Barrett HH, Furenlid LR, Kupinski MA, Patton DD, Wilson DW. Quantitative analysis of acute myocardial infarct in rat hearts with ischemia-reperfusion using a high-resolution stationary SPECT system. J Nucl Med 2002; 43(7):933-939.

4. Habraken JB, de Bruin K, Shehata M, Booij J, Bennink R, van Eck Smit BL, Busemann Sokole E. Evaluation of high-resolution pinhole SPECT using a small rotating animal. J Nucl Med 2001; 42(12):1863-1869.

5. Hirai T, Nohara R, Ogoh S, Chen LG, Kataoka K, Li XH, Fujita M, Matsumori A, Taguchi S, Sasayama S. Serial evaluation of fatty acid metabolism in rats with myocardial infarction by pinhole SPECT. J Nucl Cardiol 2001; 8(4):472-481.

6. He ZX, Shi RF, Wu YJ, Tian YQ, Liu XJ, Wang SW, Shen R, Qin XW, Gao RL, Narula J, Jain D. Direct imaging of exercise-induced myocardial ischemia with fluorine-18-labeled deoxyglucose and Tc-99m-sestamibi in coronary artery disease. Circulation 2003; 108(10):1208-1213.

7. Stoll HP, Hellwig N, Alexander C, Ozbek C, Schieffer H, Oberhausen E. Myocardial metabolic imaging by means of fluorine-18 deoxyglucose/technetium-99m sestamibi dual-isotope single-photon emission tomography. Eur J Nucl Med 1994; 
21(10):1085-1093.

8. Sandler MP, Bax JJ, Patton JA, Visser FC, Martin WH, Wijns W. Fluorine-18-fluorodeoxyglucose cardiac imaging using a modified scintillation camera. J Nucl Med 1998; 39 (12) :2035-2043.

Fig. 1.

Front view of pinhole collimator.

Fig. 2.

Side view of pinhole collimator.

Fig. 3.

Simultaneous dual-isotope SPECT images of a rat. 


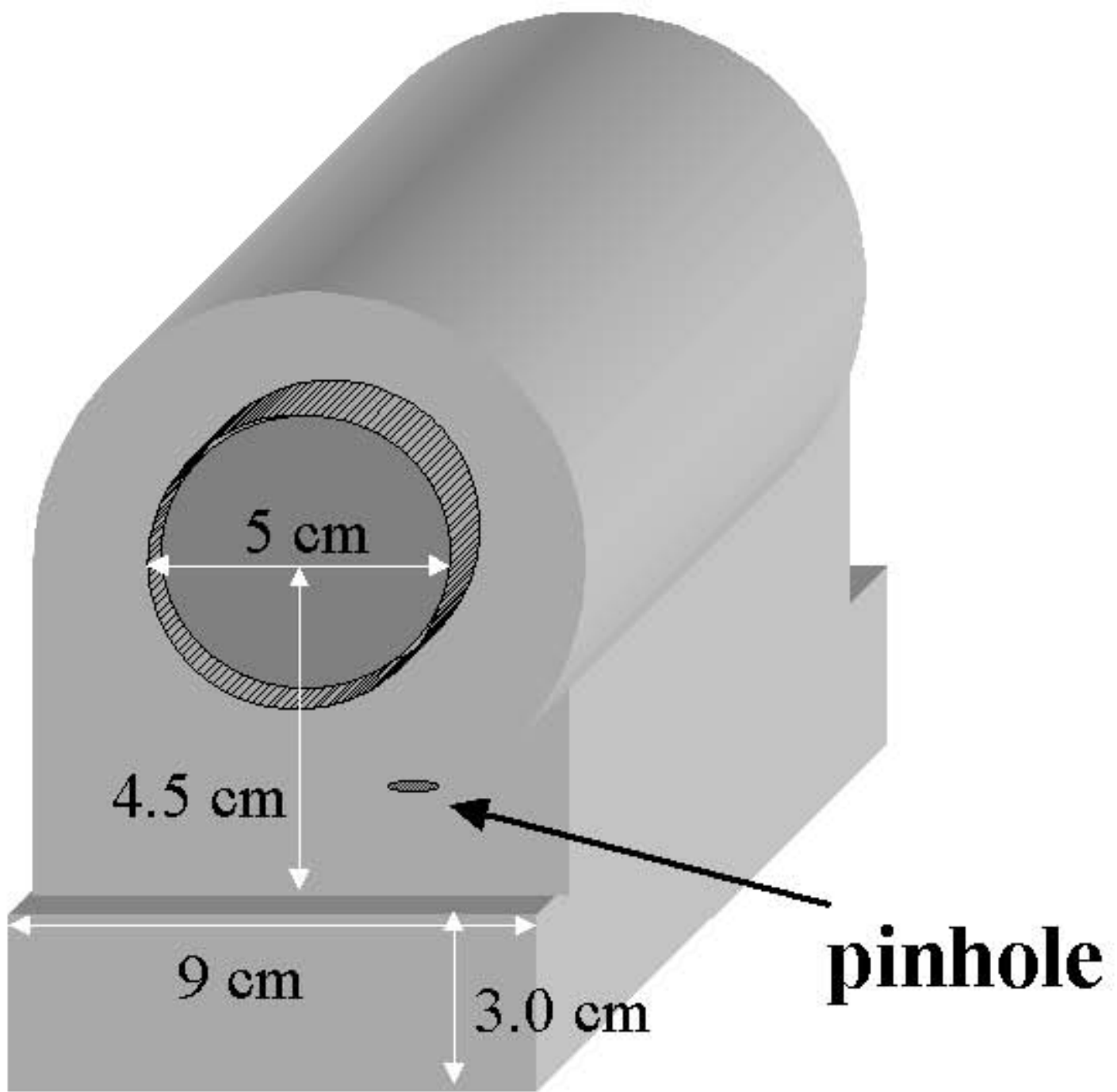

Fig. 1. Front view of pinhole collimator. 


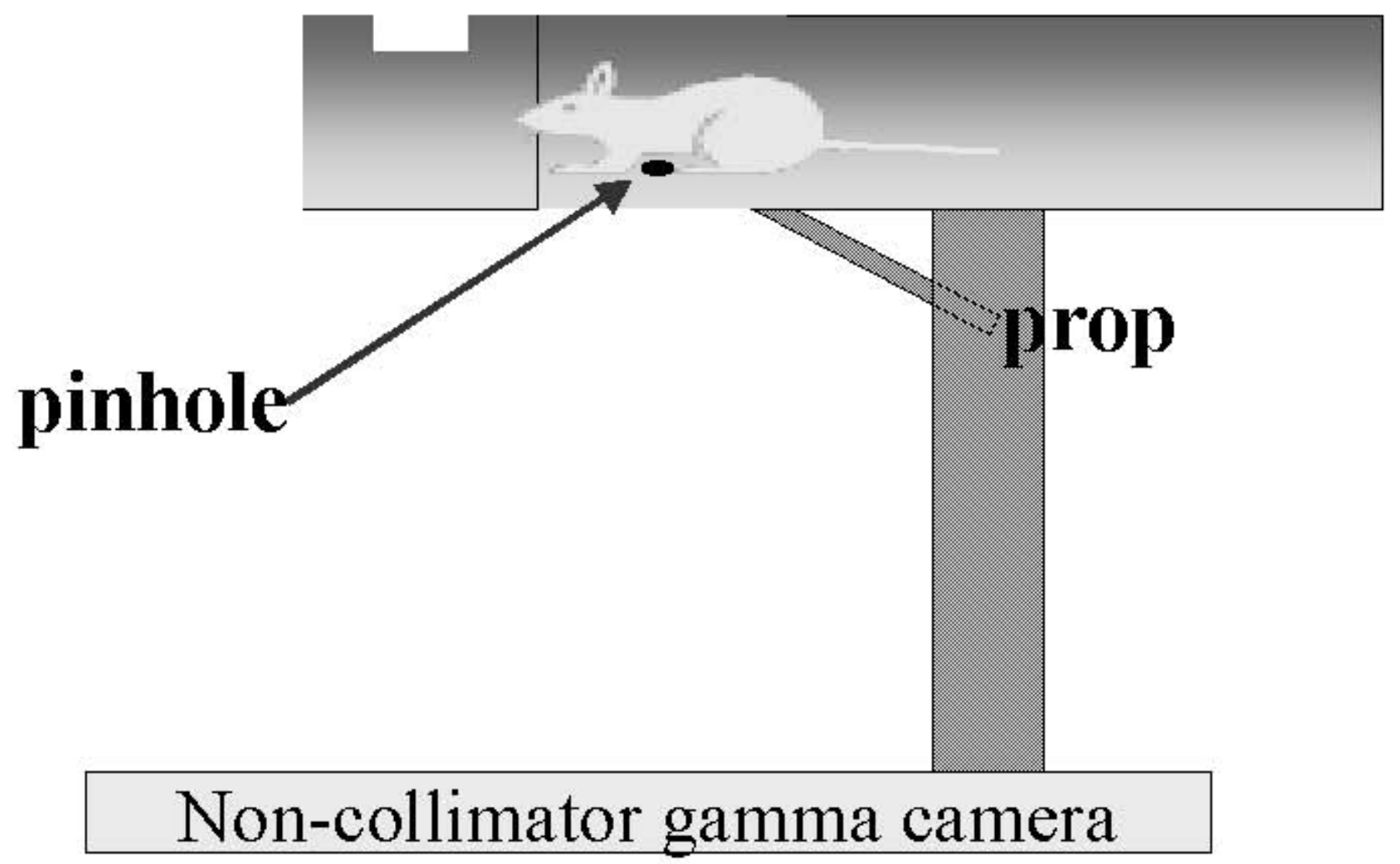

Fig. 2. Side view of pinhole collimator. 


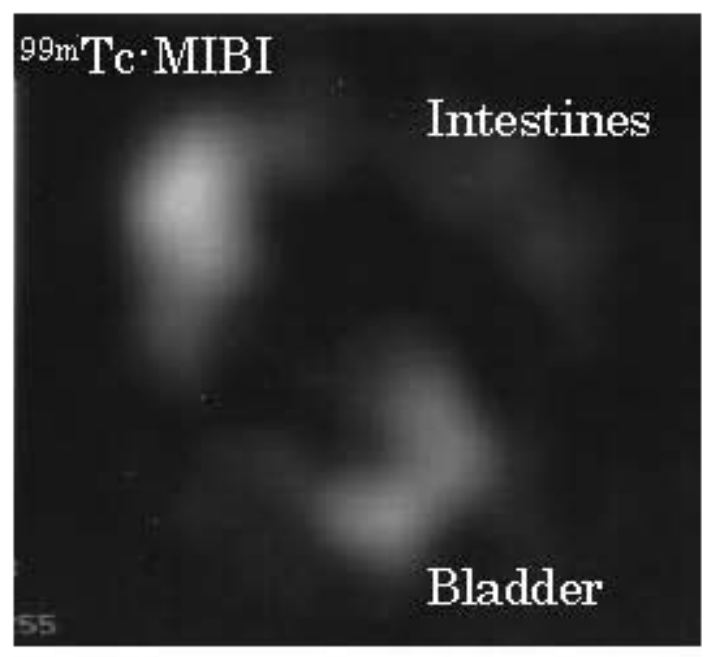

Coronal 1

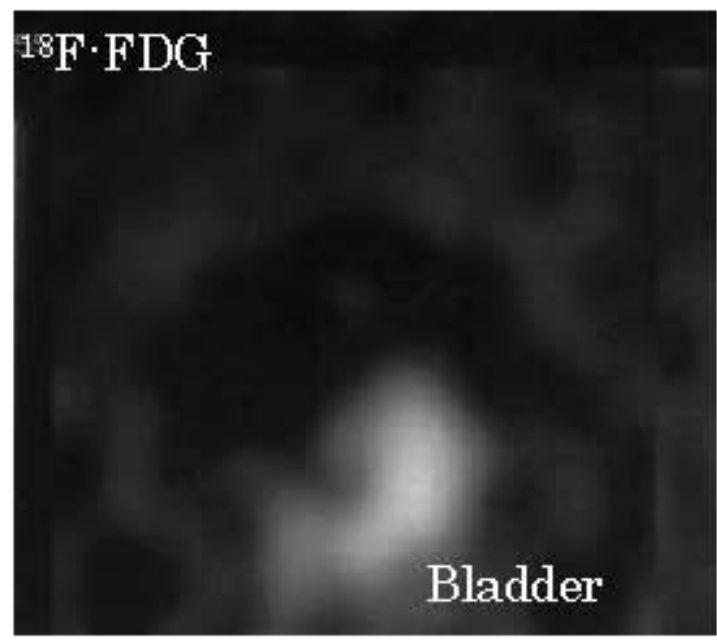

Coronal 1

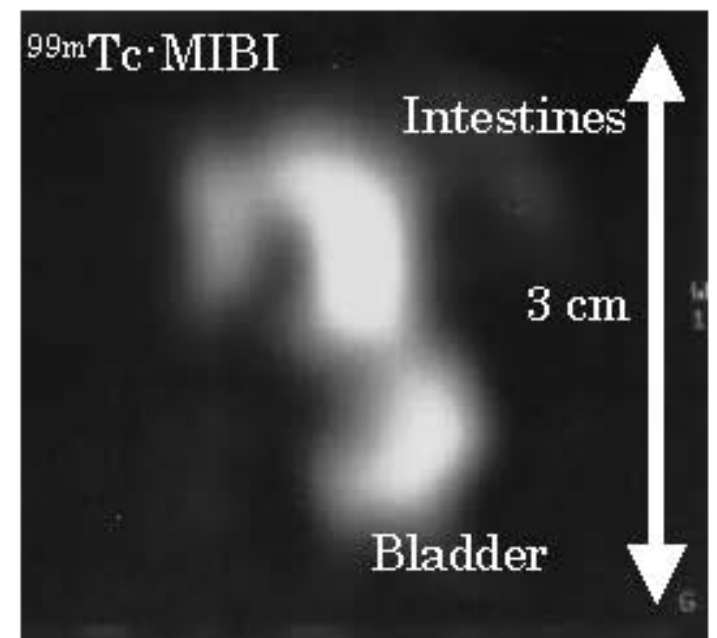

Coronal 2

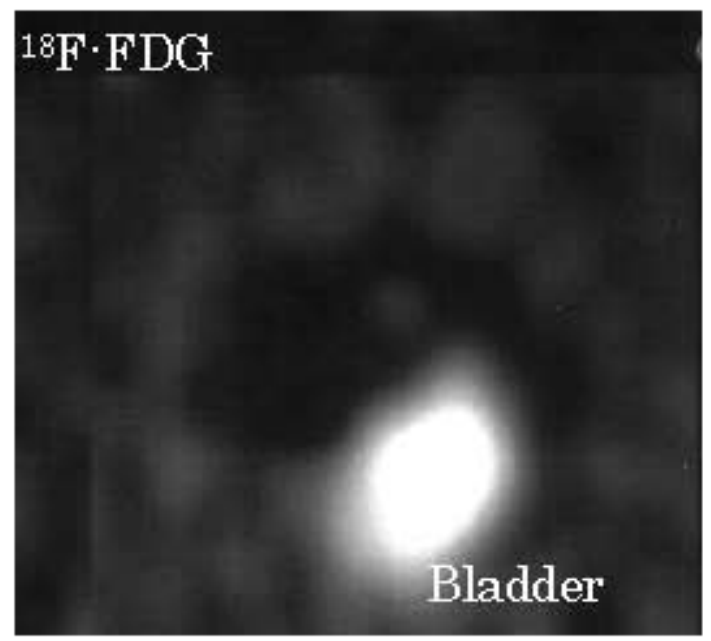

Coronal 2

Fig. 3. Simultaneous dual-isotope SPECT images of rat. 